\title{
Reflexões sobre a formação em Enfermagem no Brasil a partir da regulamentação do Sistema Único de Saúde
}

\author{
Reflections on Brazilian Nursing Education from the regulation \\ of the Unified Health System
}

\author{
Francisco Rosemiro Guimarães Ximenes Neto (https://orcid.org/0000-0002-7905-9990) ${ }^{1}$ \\ David Lopes Neto (http://orcid.org/0000-0002-0677-0853) ${ }^{2}$ \\ Isabel Cristina Kowal Olm Cunha (https://orcid.org/0000-0001-6374-5665) ${ }^{3}$ \\ Marcos Aguiar Ribeiro (https://orcid.org/0000-0001-7299-8007) ${ }^{3}$ \\ Neyson Pinheiro Freire (https://orcid.org/0000-0002-9038-9974) ${ }^{3}$ \\ Carmen Elizabeth Kalinowski (https://orcid.org/0000-0002-1324-7710) ${ }^{3}$ \\ Eliany Nazaré Oliveira (https://orcid.org/0000-0002-6408-7243) ${ }^{1}$ \\ Izabelle Mont'Alverne Napoleão Albuquerque (https://orcid.org/0000-0003-0856-5607) 1,3
}

${ }^{1}$ Universidade Estadual

Brasil.

${ }^{3}$ Escola Paulista de

\begin{abstract}
The paper reflected on the Brazilian Nursing education from the regulation of Unified Health System in a comparative historical perspective of the evolutionary processes of the Anglo-American and French schools, influencing Brazilian nursing education, as well as the guiding aspect of nursing education for the Unified Health System. Thus, nursing training initiatives guided by the National Curriculum Guidelines are developed to provide meaningful experiences in the Unified Health System's daily routine, as well as the transforming movement of Permanent Health Education in the context of the world of work. Therefore, overcoming training challenges must consider the social, political, and cultural path of the profession in order to allow changes that affect pedagogical projects, course offerings, teaching-learning methodologies, and daily work. Key words Nursing, Education, Unified Health System, Work management
\end{abstract}

Resumo $O$ artigo refletiu sobre a formação em Enfermagem no Brasil a partir da regulamentação do Sistema Único de Saúde numa perspectiva histórica comparada dos processos evolutivos das escolas anglo-americana e francesa, influenciadoras do ensino de Enfermagem no Brasil, bem como o aspecto orientador da formação em Enfermagem para o Sistema Único de Saúde. Neste sentido, são desenvolvidas inciativas de formação em Enfermagem, orientadas pelas Diretrizes Curriculares Nacionais, com vistas a propiciar vivências significativas no cotidiano do Sistema Único de Saúde, assim como o movimento transformador da Educação Permanente em Saúde no contexto do mundo do trabalho. Dessa maneira, a superação dos desafios da formação precisa considerar a trajetória social, política e cultural da profissão, de modo a possibilitar mudanças que impactam nos projetos pedagógicos, na oferta de cursos, nas metodologias de ensino-aprendizagem e no cotidiano do trabalho.

Palavras-chave Enfermagem, Educação em Enfermagem, Sistema Único de Saúde, Gestão do Trabalho 


\section{Introdução}

O processo de institucionalização do Sistema Único de Saúde (SUS), com posterior regulamentação pela Lei Orgânica da Saúde (LOS) n ${ }^{\circ}$ 8.080/1990 ${ }^{1}$ e descentralização administrativofinanceira, fomentou avanços e mudanças por conta da necessidade de um modelo de atenção à saúde que garantisse acesso a ações e serviços para a população, com base nas diretrizes e princípios que estrategicamente estabeleceram uma episteme doutrinária e uma lógica organizativa. Tal processo influenciou fortemente o mercado de trabalho em saúde, caracterizado pela produção de serviços consumidos quando produzidos, com a subjetividade própria do cuidado prestado por cada trabalhador, que afeta e é afetado, com sentidos e sentimentos próprios.

O mercado de trabalho em saúde no setor público se expandiu, tanto numa perspectiva de escala (quantitativo de trabalhadores), quanto de escopo (ampliação do campo de atuação, do rol de práticas e do protagonismo das profissões). Por conta da implantação de novas políticas, programas, ações e serviços de saúde, foram ampliados os postos de trabalho, de maneira que o eixo geográfico do trabalho em saúde passou a se deslocar dos grandes centros para o interior e os municípios se consolidam como os principais empregadores do setor ${ }^{2}$. Com isso, o SUS demandou mudanças conceituais, técnicas e ideológicas, de modo que a educação na saúde passa a configurar-se como ferramenta para a transformação da práxis e da (re)organização dos serviços ${ }^{3}$.

Quanto à formação da Enfermagem, detentora do maior contingente de trabalhadores do setor saúde, tem-se vivenciado significativas transformações, de modo a acompanhar o contexto histórico, político, econômico e social ${ }^{4}$ que repercute na produção sanitária e, consequentemente, na qualidade de vida da população brasileira. Para que isso ocorra e o processo de trabalho em Enfermagem seja coerente com as demandas sociais, a formação de Enfermeiros com qualidade é condição sine qua non para a aquisição de conhecimentos científicos, habilidades técnicas, raciocínio crítico-reflexivo e atitudes ${ }^{5}$, imprescindíveis para o desenvolvimento do cuidado holístico e humanizado voltado para as demandas de saúde individual e coletiva.

Destarte, o presente ensaio tem como objetivo refletir sobre a formação em Enfermagem no Brasil a partir da regulamentação do SUS.

\section{A Formação em Saúde e Enfermagem}

Nas últimas décadas, a formação em saúde no Brasil ganhou especial atenção, por conta da necessidade de atender as demandas do SUS e acompanhar as mudanças nos perfis demográfico e epidemiológico da população. A formação dos profissionais para o Setor Saúde, segundo Machado et al. ${ }^{6}$ deve envolver um conjunto de variáveis que permitam aliar o domínio técnico com a capacidade de agir, garantindo o fortalecimento dos princípios e diretrizes do SUS, de maneira a considerar os marcos dos direitos sociais e da atenção integral à saúde, com equidade e universalidade. Assim, a formação dos profissionais é essencial para o desenvolvimento e manutenção do sistema público de saúde 7 .

A preocupação com a formação em saúde no Brasil advém do período do Movimento pela Reforma Sanitária. Os Anais da $8^{a}$ Conferência $\mathrm{Na}-$ cional de Saúde (VIII CNS), realizada em 1986, apontavam que a política de formação em nível de graduação e pós-graduação deveria ser reformulada, no tocante a ampliação da oferta de vagas e abertura de novos cursos, a qualificação dos projetos políticos e pedagógicos, a superação de dicotomias entre ciclos básicos e clínicos/teoria e prática e os currículos estruturados com base nos diferentes níveis de atenção à saúde, buscando a integração entre ensino e serviço ${ }^{8}$.

À semelhança da VIII CNS, a $1^{\text {a }}$ Conferência Nacional de Recursos Humanos em Saúde, realizada também em 1986, apontou que os profissionais não atendiam às reais necessidades do Setor Saúde, devido formação distorcida e divorciada da prática ${ }^{9}$.

Com o processo de redemocratização do país, a Constituição Federal de $1988^{10}$ demarca em seu Artigo 200 o ordenamento da formação na saúde, de maneira que essa responsabilidade do SUS foi posteriormente consubstanciada na LOS no $8.080 / 1990^{1}$ e na Norma Operacional Básica sobre Recursos Humanos do SUS (NOB/ RH-SUS) $)^{11}$, ratificada por meio da criação, no Ministério da Saúde, da Secretaria de Gestão do Trabalho e da Educação na Saúde (SGTES) ${ }^{12}$.

Da criação e regulamentação do SUS até a atualidade, alguns problemas relacionados à formação em saúde ainda não foram superados, a exemplo da inadequação dos profissionais para atuar no sistema; a dificuldade para o desenvolvimento de práticas promotoras da saúde e de prevenção de riscos, agravos e doenças; a defasa- 
gem entre ensino e realidade e os aspectos pedagógicos; incluindo ainda, a grande expansão do ensino privado ${ }^{2,5,6}$.

Tais debilidades na formação das diversas categorias de profissionais da saúde, em especial da Enfermagem, fragilizam o processo de implantação e implementação de políticas públicas como a Estratégia Saúde da Família (ESF)/Atenção Primária à Saúde (APS), dentre outras, que requer profissionais com um olhar sensível para o território-sanitário, o "território usado, com toda sua simbologia, identidade, sentimento de pertencimento, relações sociedade-natureza, historicidade e organicidade local"13 para o desenvolvimento de um cuidado cartografado entre desejos, sentimentos, vontades e necessidades das famílias, sujeitos e comunidades em sua plenitude.

Dentre os principais obstáculos (político, ideológico e cognitivo-tecnológico) para a implantação da APS, Mendes ${ }^{14}$ apontou que ideologicamente deveria ocorrer uma mudança na cultura sanitária, que rompesse o paradigma flexneriano e buscasse estruturar um sistema de serviços, com base no paradigma da produção social da saúde, influindo em mudanças na educação das profissões, na produção do cuidado e na organização da atenção.

O ensino na saúde com as bases pedagógicas atuais ainda é reflexo do modelo proposto por Abraham Flexner, que buscou resolver o problema da qualidade do ensino médico americano no início do Século XX normatizando-o a partir do método científico, o que levou de forma paradigmática à sua hegemonia, tendo no especialismo (o mecanicismo, o biologismo, o individualismo e a ênfase no curativismo) um de seus elementos fundamentais, como modus de desenvolvimento da atenção à saúde $\mathrm{e}^{7,15}$.

$\mathrm{Na}$ Enfermagem isso pode ser constatado ao se analisar o modelo fragmentado de currículo da maioria dos cursos. Estes currículos se caracterizam pela existência de um núcleo de disciplinas básicas e outro de profissionalizantes, com foco na especialidade, além de práticas centradas na clínica hospitalar e ambulatórios especializados, priorizando o atendimento às condições agudas e a agudização das doenças crônicas ${ }^{7,16}$, levando a uma formação distante da lógica do mercado, ao passo que se deveria pensar e incentivar esta aproximação logo na graduação, com o incentivo de metodologias de ensino apropriadas para o desenvolvimento de conhecimento, habilidades e atitudes ${ }^{6}$.

\section{Vertentes influenciadoras do ensino de Enfermagem no Brasil}

A formação em Enfermagem no Brasil, em uma perspectiva histórica comparada e que distingue os fenômenos sociais em suas temporalidades com o intuito de desvelar as diacronias e as veredas expansionistas pelo mundo, é influenciada a partir dos processos evolutivos das escolas anglo-americana e francesa ${ }^{17}$.

A construção identitária do ensino de Enfermagem brasileiro remonta a 1890 , na cidade do Rio de Janeiro, com a criação da Escola Profissional de Enfermeiros e Enfermeiras (Escola de Enfermagem Alfredo Pinto), com a finalidade de formar enfermeiros e enfermeiras para trabalhar nos estabelecimentos assistenciais psiquiátricos e hospitais civis e militares, em substituição às irmãs de caridade. Para tanto foram contratadas 40 enfermeiras francesas da Escola de Salpétrière, elas atuavam como formadoras de cuidadores em um curso de Enfermagem com duração de dois anos, com componentes curriculares teórico-práticos biomédico, hospitalocêntrico e generalista, influenciados pela constituição do corpo docente predominante de médicos ${ }^{18,19}$.

Em 1923, uma nova tendência na formação de enfermeiras foi implantada com a criação da Escola de Enfermeiras do Departamento Nacional de Saúde Pública (DNSP - atual Escola de Enfermagem Anna Nery). Era pautada no modelo curricular anglo-americano ${ }^{20,21}$, conhecido como Nightingaleano, trazido ao Brasil por uma missão de enfermeiras da Fundação Rockfeller para colaborar na implantação da reforma sanitária idealizada por Carlos Chagas. O modelo repercutiu na modernização da profissão, na formação e na organização social e política da categoria, mas não conseguiu agregar ao enfermeiro uma posição social e sanitária, a partir de uma racionalidade profissional, de uma categoria liberal que produz cuidado para um mercado de trabalho com agregação da saúde e da doença ${ }^{22}$.

O modelo de formação francês trouxe como premissa a feminização, com evidente posição da profissão na estratificação social e a predominância funcionalista e hierárquica interprofissional, estando a Enfermagem em uma posição de submissão e subalternidade à hegemonia médica. Em contrapartida, o modelo de formação anglo-americano coaduna práxis com componentes essenciais para a construção alinhada da Ciência e Profissão de Enfermagem, sendo o conhecimento 
científico teórico e prático os componentes curriculares essenciais e obrigatórios para a formação. Esses dois modelos hegemônicos se refletem tanto nos projetos pedagógicos das escolas, com uma formação escolar sistematizada, como no modelo de assistência em enfermagem ${ }^{23}$ até os dias atuais.

A história da educação da Enfermagem mundial e brasileira aponta o caminho percorrido por diferentes estágios e marcos históricos de uma profissão que busca, constantemente, de forma organizada e disciplinada, envolver diferentes formas de teorização para consolidação das práticas clínicas, sociais e antropológicas, ainda fortemente pautadas na visão biologista, hospitalocêntrica e reducionista do saber.

Para romper com esta visão tradicional do ensino é necessário atuar nos Programas de PósGraduação em Enfermagem, especialmente para implantar e criar propostas de formação centradas nas demandas do setor da saúde, e produzir conhecimentos específicos para o fortalecimento da ciência da Enfermagem, transformando a sua prática social.

\section{As Diretrizes Curriculares e a Mudança na Graduação em Enfermagem}

A institucionalização das Diretrizes Curriculares Nacionais (DCN), em 2001, pelo Ministério da Educação, estimulou os cursos de graduação a reformularem seus projetos pedagógicos e currículos, estabelecendo um perfil do formando/ egresso/profissional, as competências educacionais e a descrição dos conteúdos curriculares, estágios e atividades complementares, carga horária, dentre outras ${ }^{24}$, que seriam o eixo formador dos graduandos.

As DCN além de nortear as Instituições de Ensino Superior (IES) para a construção de seus projetos pedagógicos, contribuíram para o desvelar das bases filosóficas, conceituais, políticas e metodológicas do processo de formação ${ }^{25}$, acenando para a melhoria da qualidade do ensino.

Os projetos pedagógicos passaram a ser construídos com base nas necessidades locais, o que tem sido um avanço, uma vez que aproximam a formação dos problemas reais da população, além de agregarem conteúdos vindos com o SUS e suas políticas setoriais.

Com todos os avanços proporcionados pelas DCN, ainda há uma tendência na formação em saúde de se manter o modelo tradicional de ensino flexneriano (positivista), ou ao agregá-lo a novas pedagogias, a exemplo das metodologias ativas de ensino-aprendizagem, criando assim um modelo híbrido de ensino, sem aprofundamento epistemológico da realidade das práticas sanitárias.

As metodologias ativas são compreendidas nesse texto como um conjunto de procedimentos didáticos, representados por seus métodos e técnicas de ensino, que têm o intuito de alcançar os objetivos do ensino e de aprendizagem, com a máxima eficácia ${ }^{26}$, por meio de atividades que necessitam de reflexão de ideias e desenvolvimento da capacidade de usá-las ${ }^{27}$, com o foco no desenvolvimento da autonomia do discente ${ }^{26}$, considerando sua singularidade e seu contexto ${ }^{28}$.

Na Enfermagem, o processo de implantação das DCN, ocorreu coletivamente com base nas políticas de educação e saúde, com o intuito de aproximar a formação ao SUS, o que vem induzindo e contribuindo para uma mudança paradigmática que envolve "o reconhecimento da multidimensionalidade da prática profissional (técnica/científica, ética, social, política) como forma de superar o pensar simplificado e fragmentado da realidade; a adoção da ótica pluralista das concepções de ensino, integrando a diversidade dos campos do conhecimento e uma visão global da realidade; estímulo à indissociabilidade entre as bases biológicas e sociais da atenção à saúde/enfermagem; fomento à articulação da pesquisa com o ensino e a extensão contemplando a integração teoria e prática; fomento à produção do conhecimento próprio e inovador, voltado para uma assistência de qualidade; diversificação de cenários de práticas de saúde/enfermagem; adoção de metodologias ativas de ensino-aprendizagem, tendo o aluno como sujeito do seu processo de formação; adoção da flexibilidade curricular evitando a rigidez dos pré-requisitos e dos conteúdos obrigatórios"29 (p. 99).

O impacto produzido pelas DCN apresenta alguns agravantes e desafios: a expansão dos cursos, na modalidade presencial ou a distância $(\mathrm{EaD})$, gerando o "boom" de escolas; como a Enfermagem pode "controlar" a possibilidade de acesso ao ensino, ao mesmo tempo que este é uma necessidade mundial devido a inexistência do enfermeiro em locais remotos; ser um ensino transformador, que estimule o enfermeiro a propor mudanças ou ser protagonista na implantação de políticas de saúde e no fortalecimento dos princípios da integralidade, universalidade e a equidade.

A formação em Enfermagem ao basear-se num currículo por competências, na aprendizagem significativa e centrada no estudante e nos docentes sendo facilitadores da aprendizagem, 
visa preparar, motivar e empoderar os enfermeiros para assumirem o protagonismo junto às políticas de saúde, fortalecendo a garantia do acesso da população aos sistemas universais e a produção do cuidado global, com um nível de liderança transformacional, num contexto interprofissional.

Compreendemos que a aprendizagem significativa estimula o estudante a adquirir uma nova informação que se relaciona e se ancora significativamente aos conhecimentos que já lhe pertencem, de modo natural, sem arbitrariedade ${ }^{30}$. Esta concepção dialoga com o pensamento de outros educadores contemporâneos, como Paulo Freire, na perspectiva em que nenhum aprendente deve ser tratado como um receptáculo vazio, de modo que o pré-conhecimento deve ser considerado e explorado ${ }^{31}$.

Por fim, corroboramos com a Diretriz estratégica para a Enfermagem na Região das Américas da Organização Pan-Americana da Saúde (OPAS)/Organização Mundial da Saúde (OMS) ao apontar que "investir em enfermagem significa avançar rumo ao acesso e cobertura universais de saúde, o que terá um profundo efeito sobre a saúde e o bem-estar global. Além disso, investir na formação de profissionais motivados e comprometidos com os valores da equidade e da solidariedade pode contribuir para fechar as atuais lacunas no acesso aos serviços de saúde pela população"32 (p. viii).

\section{Gestão da Educação em Saúde e Enfermagem}

A gestão do trabalho em saúde aponta como desafios essenciais o fortalecimento da articulação entre as IES e o SUS, bem como a ampliação dos processos de mudança na graduação, de maneira a garantir uma formação coerente às necessidades da população e do SUS ${ }^{33}$.

Quanto à formulação das políticas orientadoras da formação, em 2003, o Ministério da Saúde assume o protagonismo, a partir da criação da SGTES, e, em 2004, apresentou o documento "Política de Educação e Desenvolvimento para o SUS: Caminhos para a Educação Permanente em Saúde: Polos de Educação Permanente em Saúde", nele se propõe a adoção da educação permanente como estratégia para a recomposição das práticas de formação, atenção, gestão, formulação de políticas e controle social no setor da saúde ${ }^{12}$.

A partir de então, foram estimuladas iniciativas no campo da formação de profissionais para o SUS, dentre elas destacamos, o AprenderSUS, o
Projeto Vivências e Estágios na Realidade do SUS (VER-SUS), o Programa Nacional de Reorientação da Formação Profissional em Saúde (PróSaúde), o Programa de Educação pelo Trabalho para a Saúde (PET-Saúde) $)^{33-35}$, entre outros, que buscam fomentar a mudança nas graduações na saúde, a exemplos de áreas como a Enfermagem e a Medicina. Muitas dessas estratégias podem ser visualizados na Figura 1.

Tais programas, projetos e ações contribuíram para o aprimoramento da formação ao estimularem a relação entre ensino-serviço-comunidade, uma vez que os estudantes passaram a vivenciar os desafios da materialização do SUS ${ }^{36}$ em cenários reais, resultando em egressos mais preparados para atuarem nos serviços públicos de saúde.

No contexto do trabalho em saúde, para suprir a deficiência dos trabalhadores oriunda da formação universitária, o Ministério da Saúde, em fevereiro de 2004, lançou a Política Nacional de Educação Permanente em Saúde, uma estratégia para a transformação das práticas de formação, atenção, gestão, formulação de políticas, participação popular e controle social no SUS ${ }^{37}$. Dessa forma, a educação permanente em saúde movimentaria e transformaria a práxis, de modo que representa uma prática de ensino-aprendizagem e uma política de educação na saúde ${ }^{38}$. Educação permanente que produz sentidos e ressignifica a práxis.

Compreendemos que a atuação nos diversos níveis de atenção à saúde, em especial na APS, exige dos profissionais uma diversidade de saberes e práticas em áreas relacionadas à gestão sanitária, ao cuidado às famílias, sujeitos e comunidades, ao manejo das determinações e consequências sociais ${ }^{2}$, às concepções e práticas de saúde. Isso se deve aos avanços teóricos, organizacionais, tecnológicos e políticos ocorridos e à diversidade, tanto do campo da atenção, como da gestão no território, o que impõe, diariamente, novas situações a serem enfrentadas ${ }^{39}$, portanto a educação permanente e a prática interprofissional são importantes estratégias para a evolução do modelo de atenção à saúde.

\section{Demandas Profissionais do SUS e os Caminhos da Formação em Enfermagem}

O processo de implantação e implementação de diversas políticas e ações, principalmente, no nível da APS, a exemplo da ampliação do número de equipes da ESF, da criação das Equipes de Saúde Bucal (ESB), do Centro de Especialida- 


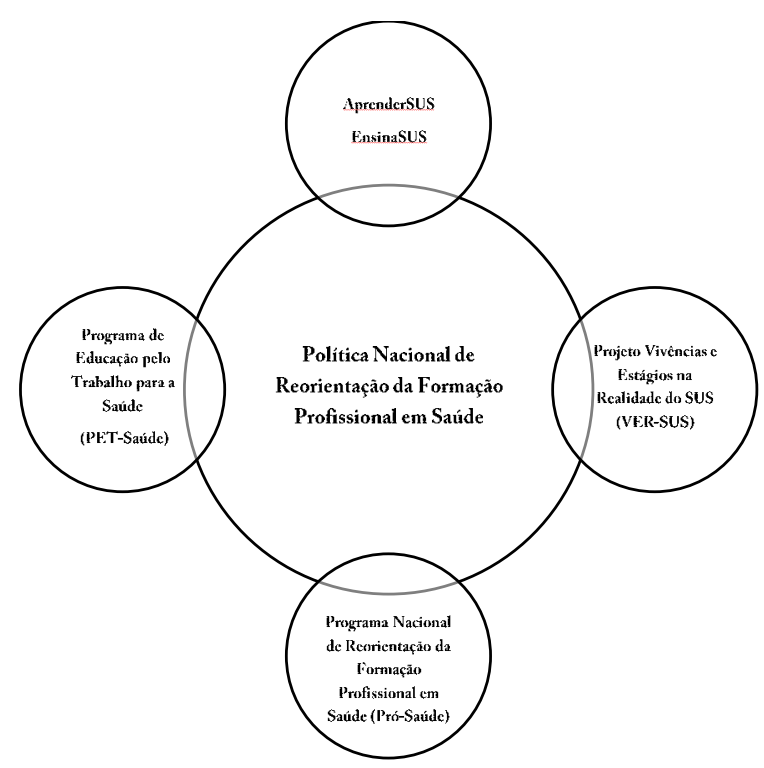

Figura 1. Estratégias para reorientação da formação profissional e fortalecimento da Gestão da Educação na Saúde.

des Odontológicas (CEO), do Núcleo de Apoio à Saúde da Família, atual Núcleo Ampliado de Saúde da Família (NASF), demandou a necessidade de formação de uma nova força de trabalho e influenciou a abertura de cursos em várias áreas como Enfermagem, Medicina e Odontologia². Com isso, a ESF passou a ser a garantia do primeiro emprego de muitos profissionais, a exemplo da Enfermagem e Medicina, e anos depois, a partir da década de 2000, os de Odontologia ${ }^{22}$ e, atualmente, das diversas outras categorias.

Tais políticas proporcionaram o alargamento do mercado de trabalho em saúde, por conseguinte motivou o atual fenômeno da mercantilização do ensino na saúde ${ }^{22}$, tanto que no período de 20 anos, os cursos de graduação na modalidade de formação presencial, das quatorze profissões da área da saúde no país, passaram de 1.032 cursos em 1995, para 5.222 em 2015, um crescimento de $506 \%{ }^{40-42}$.

Quanto aos Cursos de Enfermagem, segundo dados do Censo da Educação Superior (CES) de 2017, existem em 795 IES, 102 (12,8\%) são públicas e $693(87,16 \%)$ privadas, ofertando um total de 990 cursos entre presenciais e à distância, sendo 157 (15,9\%) públicos e 833 (84,1\%) privados. Quanto ao número de matrículas em cursos presenciais, registra-se um total de 285.097, destes
249.958 estão no setor privado e 35.139 no setor público $^{40-42}$.

O Gráfico 1 apresenta os dados da formação em Enfermagem do período de 1991 (ano seguinte da regulamentação do SUS) a 2017. Os cursos presenciais no período de 1997 a 2017 passaram de 123 a 984 , um aumento de $800 \%^{38-42}$, evidenciando um "boom" de escolas de Enfermagem, com a participação majoritária do ensino pri$\mathrm{vado}^{2}$. Nesse período, o ensino de Enfermagem em IES privadas passou de 52 para 827 escolas, um aumento de $1.590 \%$. Já nas universidades públicas passaram de 71 para 157, um aumento de $221 \%$. O ensino de Enfermagem em IES privadas mantêm-se em franca expansão, enquanto que nas públicas houve uma discreta redução de $4 \%$, de 2016 para $2017^{40-42}$.

Em decorrência do crescente mercado educacional em Enfermagem, a pesquisa "Perfil da Enfermagem no Brasil", apontou que: 57,4\% dos enfermeiros foram formados em IES privadas; com o significativo aumento do número de concluintes, a força de trabalho vivencia um processo de rejuvenescimento; apesar do volume de escolas existentes, há escassez de enfermeiros em determinadas regiões e localidades, provocando um desequilíbrio entre oferta e demanda de profissionais no país ${ }^{43}$. 


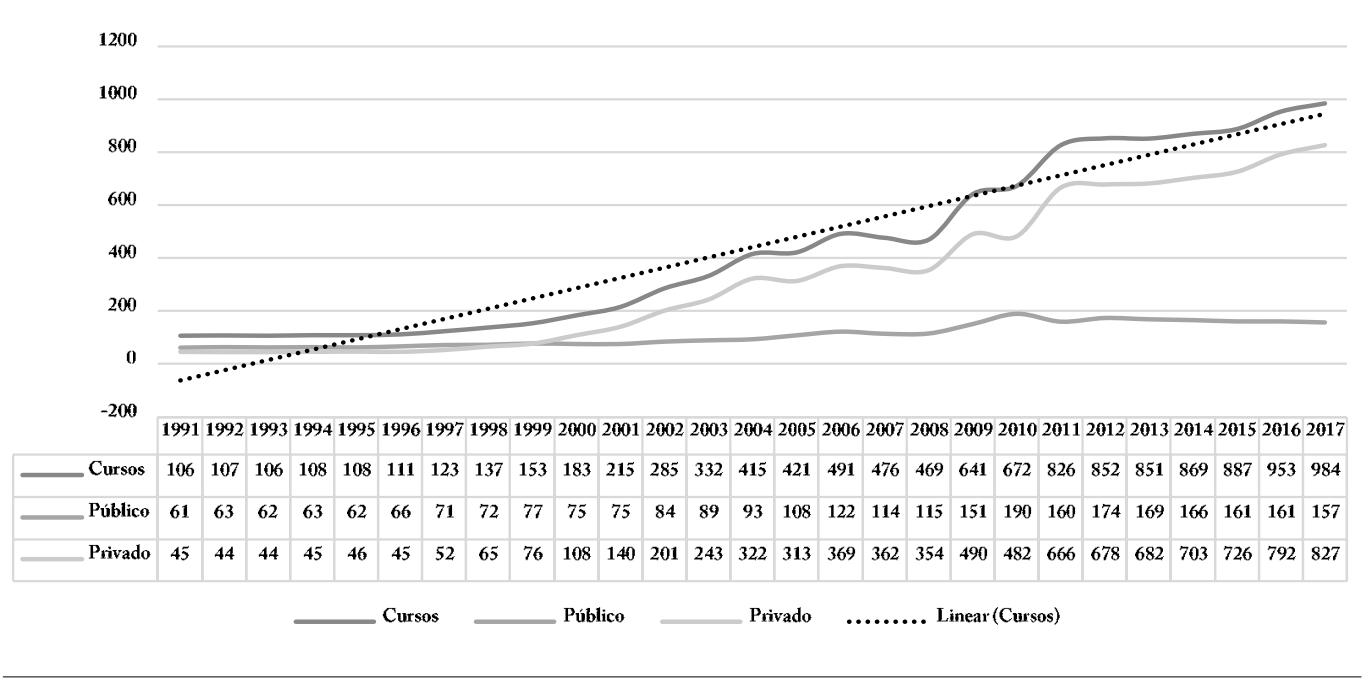

Gráfico 1. Evolução do Número dos Cursos de Enfermagem, 1991 a 2017.

Fonte: Adaptado de Instituto Nacional de Estudos e Pesquisas Educacionais Anísio Teixeira (INEP ${ }^{40,42}$. Haddad et al. ${ }^{44}$; Pierantoni et al..$^{33}$. Dados de cursos presenciais.

Quanto à distribuição dos Cursos de Enfermagem presenciais e a distância (bacharelado e licenciatura), por categoria administrativa (público e privado) das IES, segundo as Regiões Administrativas da Federação, a região Sudeste concentra $41,7 \%$ dos cursos, $37 \%$ das matrículas e $36,2 \%$ do concluintes; seguida da região Nordeste, com $24,9 \%$ dos cursos, $31 \%$ das matrículas e 32,8\% do concluintes. Apesar da região Sudeste possuir $59,8 \%$ a mais de cursos do que a região Nordeste, o número de concluintes é apenas $9,4 \%$ superior ${ }^{42}$.

Com o EaD, com a liberalização do ensino universitário e sua expansão na inciativa privada, cursos como Serviço Social, Fisioterapia, Educação Física, Ciências Biológicas e Enfermagem passaram a ser ofertados de modo à distância, o que põe em risco a qualidade destes ${ }^{2}$ e, consequentemente, a vida da população a ser cuidada por profissionais que não experimentaram e/ou vivenciaram uma rotina de práticas durante a formação universitária.

O EaD na área da Saúde no Brasil contabiliza 341.759 vagas ofertadas, sendo: $62.739(18,36 \%)$ na Enfermagem; 132.895 (38,89\%) no Serviço Social; 118.749 (34,75\%) na Educação Física; $19.392(5,67 \%)$ na Nutrição; $3.700(1,1 \%)$ na Farmácia; e, 1.617 (0,47\%) Fisioterapia. Das 341.759 vagas ofertadas na Saúde, 222.264 apresentaram candidatos, mas somente obteve 79.264 ingressos. Na Enfermagem, das 62.739 vagas ofertadas, 32.490 apresentaram candidatos, com ingresso no ano de 2017 de 9.597. O CES aponta ainda 10.029 estudantes matriculados e 127 concluíntes ${ }^{42}$.

A Enfermagem necessita de aulas e vivências práticas que propiciem o significativo encontro do aprendente com outros estudantes, com docentes e com a comunidade para o desenvolvimento de conhecimentos, habilidades e atitudes. Assim, buscar fazê-lo na modalidade $\mathrm{EaD}$ não supre as demandas da formação, pois esta exige uma base teórica sólida e o desenvolvimento de habilidades adquiridas com a prática das técnicas ${ }^{41}$, numa complexidade crescente tanto de conteúdos como na hierarquização dos serviços onde devem ser desenvolvidas as práticas. Entende-se, pois, que a formação $\mathrm{EaD}$ na saúde representa um risco para as profissões e, principalmente, para a população brasileira que fica vulnerável sendo assistida por profissionais com formação questionável, em cursos que não apresentam critérios mínimos de qualidade.

Destarte, apesar da ordenação da "formação de recursos humanos na área de saúde"10 estar previsto constitucionalmente como sendo responsabilidade do SUS, vem ocorrendo um vertiginoso crescimento dos cursos de graduação, em sua maioria no setor privado. Percebe-se que o crescente fenômeno da privatização da educação superior na saúde, com a mercantilização do ensino, está privilegiando o mercado em detri- 
mento da real necessidade da população e de seu perfil epidemiológico, contrariando a legislação sanitária e a normatização do Conselho Nacional de Saúde².

Esse crescimento deve-se, principalmente, à expansão do ensino superior, estimulada pela Lei de Diretrizes e Bases da Educação Nacional ( $n^{\circ}$ $9.394 / 1996)^{45}$, o que possibilitou o aumento do número de vagas nos grandes centros urbanos e a interiorização do ensino, a criação de instituições, além do fomentado à intensificação do processo de privatização do ensino e consequente mercantilização deste ${ }^{2}$. Tal processo foi incrementado também pelos Planos Nacionais de Educação (PNE) de 2001 a 2010 e de 2014 a 2024.

Vale destacar que o mercado educacional, aproveitando-se da flexibilização/liberalização proporcionada pela LDB, fez com que rapidamente se desse a implantação de inúmeros cursos de graduação, em diferentes regióes do país que por vezes não os comportavam.

\section{Algumas Considerações}

A formação na Saúde e na Enfermagem apresenta uma tendência crescente do ensino privado e $\mathrm{EaD}$, sem o correspondente controle e regulação estatal, o que contribui para a manutenção da iniquidade regional brasileira na oferta de vagas, o que afeta diretamente a disponibilidade e distribuição dos profissionais nos diversos prontos da RAS, desde os grandes conglomerados urbanos, a exemplo das regiões metropolitanas, até municípios de pequeno porte, áreas rurais e na Amazônia Legal, que apresentam maior dificuldade de fixar profissionais.

Apesar das diversas políticas, os avanços proporcionados com a implantação das DCN e as estratégias de Gestão da Educação na Saúde estabelecidas nas últimas décadas, a formação em Enfermagem ainda é um grande desafio, vivencia problemas e dificuldades históricas e contemporâneas, tais como: as fragilidades estruturais nos currículos universitários, que insistem em man- ter a lógica flexneriana; a prática didática voltada para a expertise do docente e não para a aprendizagem significativa e as demandas do sistema de saúde e da população; a descontextualização dos projetos pedagógicos com o cotidiano do mundo do trabalho e com os contextos sociais, econômicos, políticos, culturais e ambientais; a qualidade da formação questionável devido ao predomínio de excesso de conteúdo teórico, em detrimento às vivências práticas nos territórios sanitários; formações uniprofissionais que não consideram o processo de desenvolvimento e aprendizado colaborativo e interprofissional; e a fragmentação entre ensino teórico, extensão e pesquisa.

Pode-se depreender que embora tenhamos significativos avanços na área da formação em Saúde e Enfermagem, ainda convive-se com importantes desafios, tais como: os currículos com restritos conteúdos do campo das Ciências Sociais e Humanas, para instrumentalizar os profissionais no manejo de questões políticas, sociais, culturais e econômicas no território sanitário; fragilidade na qualificação do desenvolvimento de uma práxis humanizada, ética, crítica, ativa e integral aos usuários do SUS, buscando a integração da universidade à APS e desta com todo o sistema de serviços que compõe a RAS; pouco estímulo ao desenvolvimento docente como prática social humanizadora, além de não valorizar e experimentar novas metodologias de ensino -aprendizagem dialógicas e participativas e o uso de Tecnologias de Informação e Comunicação (TIC), entre outros.

Grandes questões estão postas à Enfermagem, essencialmente na formação do Enfermeiro, que necessita vivenciar uma base de conhecimento sólida, como a inserção de uma abordagem mais significativa, transformadora e que potencialize a construção de práticas inovadoras e de excelência à sociedade, transcendendo o instituído para consolidar-se enquanto profissão e ciência do cuidado e assumir o protagonismo junto aos sistemas e políticas de saúde, com uma liderança competente, e com isso ter o devido reconhecimento social. 


\section{Colaboradores}

FRG Ximenes Neto participou da concepção e delineamento do estudo, redação e revisão do conteúdo intelectual até a versão final do manuscrito. D Lopes Neto, ICKO Cunha, MA Ribeiro, NP Freire, CE Kalinowski, EN Oliveira e IMN Albuquerque participaram da redação e revisão do conteúdo intelectual até a versão final do manuscrito.

\section{Referências}

1. Brasil. Lei no 8.080 de 19 de setembro de 1990. Dispõe sobre as condições para a promoção, proteção e recuperação da saúde, a organização e o funcionamento dos serviços correspondentes e dá outras providências. Diário Oficial da União 1990; 20 set.

2. Machado MH, Ximenes Neto FRG. Gestão da Educação e do Trabalho em Saúde no SUS: trinta anos de avanços e desafios. Cien Saude Colet 2018; 23(6):19711979.

3. Batista CB. Movimentos de reorientação da formação em saúde e as iniciativas ministeriais para as universidades. Barbaroi 2013; 38(1):97-125.

4. Mattia BJ, Kleba ME, Prado ML. Formação em enfermagem e a prática profissional: uma revisão integrativa da literatura. Rev Bras Enferm 2018; 71(4):21572168.

5. Montanha D, Peduzzi M. Educação permanente em enfermagem: levantamento de necessidades e resultados esperados segundo a concepção dos trabalhadores. Rev Esc Enferm USP 2010; 44(3):597-604.

6. Machado MH, Vieira ALS, Oliveira E. Gestão, Trabalho e Educação em Saúde: perspectivas teórico-metodológicas. In: Baptista TWF, Azevedo CS, Machado $\mathrm{CV}$, organizadoras. Políticas, planejamento e gestão em saúde: abordagens e métodos de pesquisa. Rio de Janeiro: Fiocruz; 2015. p. 294-321.

7. Campos FE, Aguiar RAT, Belisário AS. A formação superior dos profissionais de saúde. In: Giovanella L, Escorel S, Lobato LVC, Noronha JC, Carvalho AI, organizadores. Politicas e sistema de saúde no Brasil. Rio de Janeiro: Fiocruz; 2012. 2a ed. p. 885-932.

8. Mendes EV. Reordenamento do Sistema Nacional de Saúde: visão geral. In: Brasil. Ministério da Saúde (MS). Anais da $8^{a}$ Conferência Nacional de Saúde - 1986 [documento na Internet]. Brasília: Centro de Documentação do Ministério da Saúde; 1987. p. 265297. [acessado 2019 Jul 10]. Disponível em: http:// www.ccs.saude.gov.br/cns/pdfs/8conferencia/8conf_ nac_anais.pdf

9. Brasil. Ministério da Saúde (MS). Conferência Nacional de Recursos Humanos para a Saúde: Relatório Final [relatório na Internet]. Brasília: Centro de Documentação do Ministério da Saúde; 1986. [acessado 2019 Jul 10]. Disponível em: http://bvsms.saude.gov.br/ bvs/publicacoes/0116conf_rh.pdf

10. Brasil. Constituição da República Federativa do Brasil de 1988. Diário Oficial da União 1988; 5 out.

11. Brasil. Ministério da Saúde (MS). Conselho Nacional de Saúde (CNS). Princípios e diretrizes para a gestão do trabalho no SUS (NOB/RH-SUS). $3^{\text {a }}$ ed. Brasília: MS; 2003.

12. Brasil. Secretaria de Gestão do Trabalho e da Educação na Saúde (SGTES). Política de educação e desenvolvimento para o SUS: caminhos para a educação permanente em saúde: pólos de educação permanente em saúde. Brasília: MS; 2004.

13. Ximenes Neto FRG. Gerenciamento do território na Estratégia Saúde da Família: o processo de trabalho dos gerentes [dissertação]. Fortaleza (CE): Universidade Estadual do Ceará (UECE); 2007.

14. Mendes EV. A atenção primária à saúde no SUS. Fortaleza: Escola de Saúde Pública do Ceará; 2002.

15. Mendes EV. As redes de atenção à saúde. Brasília: Organização Pan-Americana da Saúde; 2011. 
16. Mendes EV. O cuidado das condições crônicas na atenção primária à saúde: o imperativo da consolidação da estratégia da saúde da família. Brasília: Organização Pan-Americana da Saúde; 2012.

17. Silva OC. Pesquisa documental. In: Oguisso, Campos PFS, Freitas GF. Pesquisa em história da enfermagem. São Paulo: Manole; 2011. p. 339-362.

18. Duarte AP, Vasconcelos M, Silva SV. A trajetória curricular da graduação em Enfermagem no Brasil. REID 2016; 1(7):51-63.

19. Bessa MN, Amorim WM. Aspectos da formação Profissional na escola de enfermagem Alfredo Pinto (1943-1949). Esc Anna Nery 2006; 10(1):64-74.

20. Padilha MICS, Boreinstein MS, Santos I. Enfermagem História de uma Profissão. São Paulo: Difusão; 2011.

21. Peres MAA, Padilha MICS. Uniforme como signo de uma nova identidade de enfermeira no Brasil (19231931). Esc Anna Nery 2014; 18(1):112-121.

22. Ximenes Neto FRG. Trabalho do enfermeiro na Atenção Primária à Saúde No Brasil: recortes históricos e desafios profissionais [tese]. São Paulo: Universidade Federal de São Paulo; 2013.

23. Wermelinger M, Vieira M, Machado MH. Evolução da formação na equipe de enfermagem: para onde aponta a tendência histórica? DSD 2016; 1(56):134-147.

24. Brasil. Ministério da Educação. Resolução CNE/CES no 3 de 7 de novembro de 2001. Institui Diretrizes curriculares nacionais do curso de graduação em enfermagem. Diário Oficial da União; 2001.

25. Teixeira E, Fernandes JD, Andrade AC, Silva KL, Rocha MEMO, Lima RJO. Panorama dos cursos de Graduação em Enfermagem no Brasil na década das Diretrizes Curriculares Nacionais. Rev Bras Enferm 2013; 66(n. esp.):102-110.

26. Rangel ICA, Neto LS, Darido SC, Gaspari TC, Galvão Z. O ensino reflexivo como perspectiva metodológica. In: Darido SC, Rangel ICA, organizadoras. Educação física na escola. Rio de Janeiro: Guanabara Koogan; 2005. p. 103-121. (Coleção Educação Física no Ensino Superior).

27. Michael J. Where's the evidence that active learning works? Adv Physiol Educ 2006; 30(4):159-167.

28. Brighenti J, Biavatti VT, Souza TR. Metodologias de ensino-aprendizagem: uma abordagem sob a percepção dos alunos. Rev GUAL 2015; 8(3):281-304.

29. Fernandes JD, Rebouças LC. Uma década de Diretrizes Curriculares Nacionais para a Graduação em Enfermagem: avanços e desafios. Rev Bras Enferm 2013; 66(n. esp.):95-101.

30. Moreira MA. Uma Abordagem Cognitivista do Ensino de Física. Porto Alegre: Editora da Universidade; 1983.

31. Freire P. Pedagogia da autonomia: saberes necessários à prática educativa. São Paulo: Paz e Terra; 2011.

32. Organização Pan-Americana da Saúde (OPAS). Organização Mundial da Saúde (OMS). Diretriz estratégica para a Enfermagem na Região das Américas. Washington, D.C.: OPAS; 2019.

33. Pierantoni CR, França T, Magnago C, Nascimento DN, Miranda RG. Graduações em saúde no Brasil: 2000 a 2010. Rio de Janeiro: CEPESC/IMS/UERJ; 2012.

34. Dias HS, Lima LD, Teixeira M. A trajetória da política nacional de reorientação da formação profissional em saúde no SUS. Cien Saude Colet 2013; 18(6):16131624.
35. Pierantoni CR, França T, Garcia AC, Santos MR, Varella TC, Matsumoto KS. Gestão do trabalho e da educação em saúde. Rio de Janeiro: CEPESC/IMS/UERJ/ ObservaRH; 2012.

36. Amaral VF, Cavalcante ASP, Farias QLT, Ribeiro MA, Araújo JDG, Gomes DF. Mobilizando estudantes em defesa do Sistema Único de Saúde (SUS): experiências interprofissionais do VER-SUS - Sobral, CE, Brasil. Interface (Botucatu) 2018; 22(Suppl 2):1787-1797.

37. Brasil. Ministério da Saúde (MS). Portaria GM/MS no 198 de 13 de fevereiro de 2004. Institui a Política Nacional de Educação Permanente em Saúde como estratégia do Sistema Único de Saúde para a formação e o desenvolvimento de trabalhadores para o setor e dá outras providências. Diário Oficial da União; 2004.

38. Ceccim RB, Ferla AA. Educação permanente em saúde. In: Pereira IB, Lima JCF. Dicionário da educação profissional em saúde. $2^{\text {a }}$ ed. rev. ampl. Rio de Janeiro: EPSJV; 2008. p. 162-168.

39. Ximenes Neto FRG, Sampaio JJC. Gerentes do território na Estratégia Saúde da Família: análise e perfil de necessidades de qualificação. Rev Bras Enferm 2007; 60(6):687-695.

40. Brasil. Ministério da Educação (MEC). Instituto Nacional de Estudos e Pesquisas Educacionais Anísio Teixeira (INEP). Censo da Educação Superior: resumos técnicos. [página na Internet]. [acessado 2019 Jun 11]. Disponível em: http:/inep.gov.br/web/guest/resumos-tecnicos 1

41. Vieira ALS, Moyses NMN. Trajetória da graduação das catorze profissões de saúde no Brasil. Saude Debate 2017; 41(113):401-414.

42. Brasil. Ministério da Educação (MEC). Instituto Nacional de Estudos e Pesquisas Educacionais Anísio Teixeira (INEP). Censo da Educação Superior 2017 Divulgação dos principais resultados [documento na Internet]. 2018 [acessado 2019 Jun 11]. Disponível em: http://portal.mec.gov.br/docman/setembro-2018-pdf /97041-apresentac-a-o-censo-superior-ultimo/file

43. Machado MH, coordenadora. Pesquisa Perfil da Enfermagem no Brasil: Relatório Final [relatório na Internet]. Rio de Janeiro: Nerhus-Daps-Ensp/Fiocruz; 2017. [acessado 2019 Ago 10]. Disponível em: http:// www.cofen.gov.br/perfilenfermagem/pdfs/relatoriofinal.pdf

44. Haddad AE, Pierantoni CR, Ristoff D, Xavier IM, Giolo J, Silva LB, organizadores. A trajetória dos cursos de graduação na área da saúde: 1991-2004 [livro na Internet]. Brasília: Instituto Nacional de Estudos e Pesquisas Educacionais Anísio Teixeira; 2006. [acessado 2019 Jun 11]. Disponível em: http://portal.inep. gov.br/informacao-da-publicacao/-/asset_publisher/ 6JYIsGMAMkW1/document/id/489343

45. Brasil. Lei no 9.394 de 20 de dezembro de 1996. Estabelece as diretrizes e bases da educação nacional. Diário Oficial da União 1996; 23 dez.

Artigo apresentado em 30/04/2019

Aprovado em 20/08/2019

Versão final apresentada em 20/09/2019 